\title{
How can higher-yield farming help to spare nature?
}

Ben Phalan (1), ${ }^{*}$, Rhys E. Green (1),(2), Lynn V. Dicks (1), Graziela Dotta (3), Claire Feniuk (1), Anthony Lamb (1), Bernardo B. N. Strassburg (4), (5), David R. Williams (1), Erasmus K. H. J. zu Ermgassen (1), Andrew Balmford (1)

(1) Conservation Science Group, Department of Zoology, University of Cambridge, Cambridge CB2 3EJ, UK.

(2) RSPB Centre for Conservation Science, Royal Society for the Prote">2RSPB Centre for Conservation Science, Royal Society for the Protection of Birds, Sandy SG19 2DL, UK.

(3) Laboratório de Ornitologia, Museu de Ciências e Tecnologia, PUC-RS, 6681, Porto Alegre, Brazil.

(4) International Institute for Sustainability, 22460-320 Rio de Janeiro, Brazil.

(5) Rio Conservation and Sustainability Science Centre, Department of Geography and the Environment, Pontifícia Universidade Católica, 22453-900 Rio de Janeiro, Brazil.

*Corresponding author. E-mail: btp22@cam.ac.uk

Expansion of land area used for agriculture is a leading cause of biodiversity loss and greenhouse gas emissions, particularly in the tropics. One potential way to reduce these impacts is to increase food production per unit area (yield) on existing farmland, so as to minimize farmland area and to spare land for habitat conservation or restoration. There is now widespread evidence that such a strategy could benefit a large proportion of wild species, provided that spared land is conserved as natural habitat (1). However, the scope for yield growth to spare land by lowering food prices and, hence, incentives for clearance ("passive" land sparing) can be undermined if lower prices stimulate demand and if higher yields raise profits, encouraging agricultural expansion and increasing the opportunity cost of conservation $(2,3)$. We offer a first description of four categories of "active" land-sparing mechanisms that could overcome these rebound effects by linking yield increases with habitat protection or restoration (table S1). The effectiveness, limitations, and potential for unintended consequences of these mechanisms have yet to be systematically tested, but in each case, we describe real-world interventions that illustrate how intentional links between yield increases and land sparing might be developed.

FOUR LINKING MECHANISMS. Land-use zoning. Zoning some land for conservation and some for agriculture limits agricultural expansion, provides security to landholders investing in agricultural productivity, and can incentivize yield increases to compensate for the scarcity of available land ["Boserupian innovation" (4)]. However, zoning does not drive yield increases in agricultural zones directly. Hence, there is a risk of its leading to displacement of production outside the regions subject to zoning. Such "leakage" might be less likely where zoning restrictions are placed on the expansion of export commodities for which demand shows high price elasticity, rather than on staple foods (2).

In Costa Rica, after the government zoned forests as off-limits for agricultural expansion, the rate of clearance of mature forests halved (5). Export-oriented agriculture shifted from cattle pasture toward high-yielding pineapple and banana crop, (for fuller information and references for this and other case studies, see supplementary materials (SM). Beef production declined, albeit temporarily, 
whereas production of pineapples and other crops has continued to increase. The risk of leakage could be reduced by prioritizing lessproductive land for conservation to minimize loss of production and by combining zoning with other interventions (6).

Economic instruments, such as payments, land taxes, and subsidies. In principle, these can be tailored to stimulate yield increases, discourage habitat conversion, and make receipt of benefits conditional on habitat conservation. Incentive programs often involve contracts, and difficulties can arise through hidden actions and information asymmetries. For example, recipients might conceal breaches of contract or accept money for actions they would have carried out anyway. These risks can be reduced by building trust, understanding the people and places where interventions occur, developing cost-effective monitoring, and enforcing contracts.

An incentive program that has successfully spared land has been implemented in the Spiti Valley of Himalayan India (7). In exchange for designating land set-asides for the recovery of snow leopard prey, herders receive payments and technical assistance to reduce livestock losses to snow leopards (improving yield) and to organize insurance against losses. The program, which was developed collaboratively with herders and local government to ensure that it addresses local priorities, reduced snow leopard predation of livestock by two-thirds in its first 4 years and eliminated snow leopard killings.

Spatially strategic deployment of technology, infrastructure, or agronomic knowledge. Land sparing can be encouraged if yield-enhancing measures (such as technical advice on soil, nutrient, or water management; improved germplasm; multiple cropping; integrated pest and disease control; and improved access to roads or irrigation) are intentionally directed toward certain areas and not others. Such interventions could enhance yields and reduce post-harvest losses in established farmlands, while avoiding the risks involved in stimulating agriculture in areas of extensive natural habitat (8). Increasing yields of staple crops, for which demand is inelastic to price changes, appears more likely to support land sparing than increasing yields of luxury or export crops (2). A limitation of strategic deployment is that it encourages yield increases directly but only protects natural habitats indirectly, by reducing pressure for conversion. It will often be necessary to combine this mechanism with others, especially land-use zoning. A key challenge is to ensure that benefits and costs are not unfairly distributed.

In the Philippine province of Palawan, introduction of irrigation helped lowland rice farmers produce two crops per year rather than one (9). They met their higher labor demands by employing upland farmers, who used part of their new-found income to invest in fertilizers, which improved their own yields and reduced their need to clear forests. Deforestation rates in the uplands halved. Larger and poorer households were those most likely to benefit. Nevertheless, addressing social justice remains practically and ethically complex, is often hampered by unequal power relations and may often require additional measures, such as increasing nonagricultural job opportunities for marginalized groups. 
Standards and certification. Voluntary standards could link yield growth to conservation by requiring habitat protection, defining sustainable yield-increasing practices, monitoring compliance, and rewarding good performance with market access and price premiums. Sparing or restoring natural habitats at farm scale can be more beneficial for biodiversity than certifying lower-yielding "wildlifefriendly" practices (10). To maximize their contribution to landscape-level conservation, certification schemes should widen their focus from individual farms to coordinated actions by groups of farmers in places where potential conservation gains are greatest.

Participating farmers in the Ibis rice scheme in northern Cambodia receive technical assistance and a price premium, which makes it easier to afford simple technology and additional labor (11). At the same time, they agree to a village-level land-use plan that protects habitats. These agreements are maintained in part by social pressure: A major infraction would put everyone's benefits at risk. Together with other initiatives, the scheme has reduced deforestation and increased rice harvests. It illustrates one way of making landscape conservation relevant and feasible for individual farmers.

CONDITIONS AND SYNERGIES. Some conditions make successful implementation of land-sparing mechanisms more likely. Labor- and capital-intensive technologies and practices are those most likely to be conducive to land sparing (8). Knowledge networks can also help improve implementation of sustainability standards or payment schemes (12). For example, thousands of Landcare groups in Australia share knowledge on accessing funds, conserving habitats, and improving agricultural techniques. Landcare participants are more likely to protect and restore native vegetation and to adopt practices that sustain agricultural yields (13). Markets also matter. For commodities with globalized markets and elastic demand, limiting rebound effects through demand-side measures and restrictions on land use will be crucial. In the case of staples grown by smallholders, supporting them to increase their yields (and thereby, limit leakage) might be more appropriate.

Each mechanism is most likely to be effective if implemented in synergy with others, so that strong protection is provided to habitats and adequate support is provided to farmers to increase their yields. Command-and-control zoning policies will more likely be accepted as legitimate if accompanied by incentives, improved access to technology and infrastructure, and knowledgesharing (14). Because of the risk of rebound effects, strategic deployment will often have to be integrated with mechanisms, such as zoning, that apply over large areas. Environmental and agricultural policies need to be coordinated to work in synergy rather than in conflict.

Brazil provides an example of how multiple policy interventions can work together. Natural habitats are conserved through several instruments including protected areas, indigenous reserves, and Forest Code requirements on private lands (15). Government-subsidized loans are provided to farmers to increase productivity on degraded pastureland. Partly due to these initiatives, and despite widespread noncompliance with the Forest Code, deforestation in the Brazilian Amazon declined steeply after 2004, whereas agricultural production continued to grow. 
Whether these trends can be sustained and replicated elsewhere will depend largely on the political will to deliver strong environmental governance. There is a risk that environmental regulations will be corrupted or diluted by powerful special interests, as happened in Europe with the Common Agricultural Policy (16). Further efforts to reduce habitat loss must do so while safeguarding the interests of smallholders, as agricultural credit programs in Brazil seek to do by supporting family farms. In many parts of the world, higher yields have eroded not only on-farm biodiversity but also water, soil, and air quality. Much remains to be done to reduce these impacts by applying improved agronomic and agroecological knowledge (17).

Harnessing the potential of higher-yield farming to make space for nature at scales that matter will not be straightforward, but the examples described here illustrate that it can be done. The challenge is to move on from thinking about higher yields simply as a means to produce more food and to use them to free up land for conserving biodiversity and ecosystem services. Reconciling agriculture and conservation is one of this century's greatest challenges. We hope that by describing some promising solutions, we can stimulate the proposal, testing, and application of many more.

Supplementary Materials

www.sciencemag/content/351/6272/450/suppl/DC1

\section{References and Notes}

$\leftrightarrow$ A. Balmford, R. Green, B. Phalan, Daedalus 144, 57 (2015).CrossRef

$\triangleleft$ E. F. Lambin, P. Meyfroidt, Proc. Natl. Acad. Sci. U.S.A. 108, 3465 (2011).Abstract/FREE Full Text

$\triangleleft$ D. Byerlee et al., Glob. Food Secur. 3, 92 (2014).CrossRef

$\triangleleft$ E. Boserup, The Conditions of Agricultural Growth: The Economics of Agrarian Change under Population Pressure (Allen \& Unwin, London, 1965).

$\triangleleft$ M. E. Fagan et al., Environ. Res. Lett. 8, 034017 (2013).CrossRef

$\triangleleft$ A. E. Latawiec, B. B. Strassburg, P. H. Brancalion, R. R. Rodrigues, T. Gardner, Front. Ecol. Environ 13, 211 (2015).CrossRef

$\triangleleft$ R. M. Jackson, C. Mishra, T. M. McCarthy, S. B. Ale, in The Biology and Conservation of Wild Felids (Oxford Univ. Press, Oxford, 2010), pp. 417-430.

$\leftrightarrow$ A. Angelsen, Proc. Natl. Acad. Sci. U.S.A. 107, 19639 (2010).Abstract/FREE Full Text

$\triangleleft$ G. Shively, S. Pagiola, Environ. Dev. Econ. 9, 241 (2004).CrossRefWeb of Science

$\leftrightarrow$ R. B. Chandler et al., Conserv. Biol. 27, 785 (2013).CrossRefMedline

$\triangleleft$ T. Clements, E. J. Milner-Gulland, Conserv. Biol. 29, 78 (2015).CrossRefMedline

$\triangleleft$ J. R. Franks, S. B. Emery, Land Use Policy 30, 847 (2013).CrossRef 
$\triangleleft$ A. Curtis, D. Lucas, M. Nurse, M. Skeen, Achieving NRM outcomes through voluntary action: lessons from landcare (Charles Sturt Univ. and Department of Sustainability and Environment, Melbourne, Australia, 2008).

$\leftrightarrow$ E. F. Lambin et al., Glob. Environ. Change 28, 129 (2014).CrossRef

$\leftrightarrow$ D. Nepstad et al., Science 344, 1118 (2014).Abstract/FREE Full Text

$\triangleleft$ G. Pe'er et al., Science 344, 1090 (2014).Abstract/FREE Full Text

$\triangleleft$ R. Bommarco, D. Kleijn, S. G. Potts, Trends Ecol. Evol. 28, 230 (2013).CrossRefMedlineWeb of Science

Acknowledgments: We thank T. Gardner, M. Fagan, A. John, A. Mould, G. Shively, E. Beauchamp, C. Mishra, T. Clements, N. Selva, and three anonymous reviewers for comments. Funding: Zukerman fellowship, King's College, Cambridge (B.P.); Natural Environment Research Council NE/K015419/1 (L.V.D.); Gordon and Betty Moore Foundation and Norwegian Agency for Development Cooperation (B.B.N.S.); Biotechnology and Biological Sciences Research Council BB/J014540/1 (E.K.H.J.Z.E.). 